\title{
The Role of Molecular Imaging in the Diagnosis and Management of Neuropsychiatric Disorders
}

\author{
Lie-Hang Shen,, ${ }^{1}$ Yu-Chin Tseng, ${ }^{1}$ Mei-Hsiu Liao, ${ }^{1,2}$ and Ying-Kai Fu ${ }^{1,3}$ \\ ${ }^{1}$ Institute of Nuclear Energy Research, Lungtan, Taoyuan 325, Taiwan \\ ${ }^{2}$ Institute of Pharmacology, School of Medicine, National Yang-Ming University, Taipei 112, Taiwan \\ ${ }^{3}$ Department of Chemistry, Chung Yuan Christian University, Chung-Li 320, Taiwan
}

Correspondence should be addressed to Ying-Kai Fu, fufrank@iner.gov.tw

Received 27 December 2010; Accepted 15 February 2011

Academic Editor: David J. Yang

Copyright (C) 2011 Lie-Hang Shen et al. This is an open access article distributed under the Creative Commons Attribution License, which permits unrestricted use, distribution, and reproduction in any medium, provided the original work is properly cited.

\begin{abstract}
Neuropsychiatric disorders are becoming a major socioeconomic burden to modern society. In recent years, a dramatic expansion of tools has facilitated the study of the molecular basis of neuropsychiatric disorders. Molecular imaging has enabled the noninvasive characterization and quantification of biological processes at the cellular, tissue, and organism levels in intact living subjects. This technology has revolutionized the practice of medicine and has become critical to quality health care. New advances in research on molecular imaging hold promise for personalized medicine in neuropsychiatric disorders, with adjusted therapeutic doses, predictable responses, reduced adverse drug reactions, early diagnosis, and personal health planning. In this paper, we discuss the development of radiotracers for imaging dopaminergic, serotonergic, and noradrenergic systems and $\beta$-amyloid plaques. We will underline the role of molecular imaging technologies in various neuropsychiatric disorders, describe their unique strengths and limitations, and suggest future directions in the diagnosis and management of neuropsychiatric disorders.
\end{abstract}

\section{Introduction}

Modern neuroimaging offers tremendous opportunities for gaining insights into the molecular basis of neuropsychiatric disorders. Molecular imaging shows how specific tissues are functioning. This contrasts with conventional diagnostic imaging procedures, which simply provide anatomical or structural pictures of organs and tissues. Several techniques including functional magnetic resonance imaging (fMRI) and nuclear medicine imaging can measure regional changes in cerebral activity; however, nuclear medicine imaging is the only tool for direct measurements of neurotransmitter levels and the distribution, density, and activity of receptors or transporters. In contrast to fMRI, nuclear medicine imaging involves the administration of radioactively labeled tracers, which decay over time by emitting gamma rays that can be detected by a positron emission tomography (PET) or single photon emission computed tomography (SPECT) scanner. The radioisotopes used in PET can reach a more stable configuration by the emission of positrons, which travel a short distance and collide with electrons. The annihilation of positron and electron produces 2 gamma rays, $511 \mathrm{keV}$ each, which are emitted in opposite directions. In PET, annihilation coincidence detection is used in lieu of absorptive collimation to determine the directionality of the detected photons; this partially explains the greater spatial resolution and sensitivity of PET. However, compared with SPECT, PET is more expensive and less readily available. The most commonly used radioisotopes for labeling PET radiopharmaceuticals are ${ }^{11} \mathrm{C}$ and ${ }^{18} \mathrm{~F} \cdot{ }^{11} \mathrm{C}$ has a short halflife of approximately $20 \mathrm{~min}$, which allows multiple studies in the same day. In contrast, ${ }^{18} \mathrm{~F}$ has a half-life of nearly $2 \mathrm{~h}$, which allows shipment of tracers over considerable distances to PET centers that do not have a cyclotron. SPECT radiotracers typically have longer physical half-lives than most PET tracers; this may partially compensate for their disadvantages, particularly when measurements over several hours are required to eliminate nonspecific binding and reach equilibrium.

A major advantage of nuclear medicine imaging is the extraordinarily high sensitivity $\left(10^{-9}\right.$ to $\left.10^{-12} \mathrm{M}\right)$, many orders of magnitude greater than the sensitivities available 
with MRI $\left(10^{-4} \mathrm{M}\right)$. Because many molecules relevant to neuropsychiatric disorders are present at concentrations below $10^{-8} \mathrm{M}$, nuclear medicine imaging is currently the only available in vivo method capable of quantifying subtle cerebral pathophysiological changes that might occur before neurostructural abnormalities take place [1].

PET and SPECT can measure biological processes, like glucose consumption and regional cerebral blood flow (rCBF), which may change in various neuropsychiatric disorders. In PET imaging, ${ }^{18} \mathrm{~F}$-fluorodeoxyglucose $\left({ }^{18} \mathrm{~F}-\mathrm{FDG}\right)$ is the most commonly used radiopharmaceutical. Active neurons have higher metabolic rates and higher glucose uptake rates than less active neurons. Similarly, active brain regions have higher regional cerebral blood flow ( $\mathrm{rCBF}$ ) compared to less active brain regions. With PET, intravenous ${ }^{15} \mathrm{O}-\mathrm{H}_{2} \mathrm{O}$ can be administered to measure rCBF. In SPECT imaging, ${ }^{99 \mathrm{~m}} \mathrm{Tc}-$ hexamethylpropyleneamine oxime $\left({ }^{99 \mathrm{~m}} \mathrm{Tc}-\right.$ HMPAO) is the most commonly used radiopharmaceutical.

Radioligands must fulfill several criteria for successful PET or SPECT imaging, including stability of labeling, sufficient affinity and high selectivity for the specific receptor, combined with low nonspecific binding to brain tissues that do not contain the receptor of interest, and rapid permeation through the blood-brain barrier to permit tracers access to receptors [2]. Selective radioligands are available for various transmitter systems; these enable the visualization of receptor distributions in the normal brain and the detection of changes in receptor binding during various physiologic activities or under pathologic conditions. Quantitative imaging has gained clinical importance for measuring the activities of several receptors/transporters and molecular targets, for example, quantification of dopamine transporters for detecting loss of functional dopaminergic neuron terminals in the striatum, quantification of dopamine D2 receptors for studies of movement disorders and for assessments of receptor occupancy by neuroleptic drugs, quantification of serotonin (5-hydroxytryptamine, or 5-HT) receptors in affective disorders, quantification of serotonin and norepinephrine transporters for assessment of occupancy of antidepressants, and quantification of $\beta$ amyloid and acetylcholinesterase as markers of cognitive and memory impairments. The clinical and experimental relevance of these findings should not be underestimated. Neuroprotective and disease-modifying drug research has intensified, and results rely heavily on accurate, early diagnoses.

New advances in neuroimaging offer the promise of more personalized treatment for individuals with neuropsychiatric disorders. Molecular imaging can provide patient-specific information that allows treatment to be tailored to the specific biological attributes of both the disease and the patient. The eventual success of experimental therapies rests on understanding the mechanisms of the various neuropsychiatric disorders, early and accurate diagnoses, and noninvasive approaches for monitoring the progression of disease and the response to treatment.

Although nuclear imaging is a promising technique, several barriers must be addressed to facilitate its successful application to neuropsychiatric disorders. The major barrier to nuclear medicine imaging of molecular targets may be the difficulty in developing radiotracers. Another barrier is the lack of current evidence to support the use of molecular imaging as a diagnostic tool in clinical practice. The radiotracers used as biomarkers in neuropsychiatric disorders must have both biologic relevance and a strong linkage to the clinical outcome of interest. Despite the development of a large number of radioactive ligands for receptors, most do not fulfill the criteria for a good label, and only a few have been applied in clinical nuclear medicine. Physical barriers include limited anatomic resolution and the need for higher sensitivity. However, recent developments in improved detector crystals and three-dimensional image acquisition have markedly enhanced both sensitivity and resolution. Radiotracer imaging with PET and, to a lesser extent, with SPECT is ideally suited for in vivo applications, due to its superior anatomic resolution.

\section{Parkinson's Disease and Related Disorders}

Parkinson's disease (PD), the second most common neurodegenerative disorder, is characterized by severe loss of nigrostriatal neurons, which results in a deficiency of the neurotransmitter, dopamine [3]. Clinical diagnosis of PD relies on the presence of characteristic motor symptoms, including bradykinesia, rigidity, and resting tremors. In addition, nonmotor features have been increasingly recognized as early symptoms $[4,5]$. Nonetheless, an early differential diagnosis can be difficult, particularly because the initial presentation may include overlapping clinical features, like essential tremor, vascular parkinsonism, drug-induced parkinsonism, and atypical parkinsonian syndrome (i.e., multiple system atrophy and progressive supranuclear palsy). Often, the clinical diagnosis of PD is supported by a positive response to dopaminergic drugs, particularly levodopa. However, some patients with pathologically confirmed PD respond poorly to levodopa; conversely, other patients with early multiple system atrophy or progressive supranuclear palsy respond well to drug treatment. Previously, the rate of misdiagnosis of idiopathic PD was as high as $24 \%[6,7]$.

The evolution of neuroimaging techniques over the past several years has yielded unprecedented information about the degenerative processes in PD and other movement disorders. PET and SPECT techniques have been successfully employed in identifying dopaminergic dysfunction in PD by detecting changes in brain levodopa, glucose metabolism, and dopamine transporter binding. Several tracers can be employed to assess the integrity of dopamine terminals in PD. First, dopa decarboxylase activity and dopamine turnover can both be measured with ${ }^{18} \mathrm{~F}$-FDOPA PET. Second, the availability of presynaptic dopamine transporters (DATs) can be assessed with various tracers, which are typically tropane based. Third, vesicle monoamine density in dopamine terminals can be evaluated with ${ }^{11} \mathrm{C}$ dihydrotetrabenazine PET $[8,9]$.

The uptake of ${ }^{18} \mathrm{~F}$-FDOPA reflects both the density of the axonal terminal plexus and the activity of the striatal aromatic amino acid decarboxylase (AADC), the 

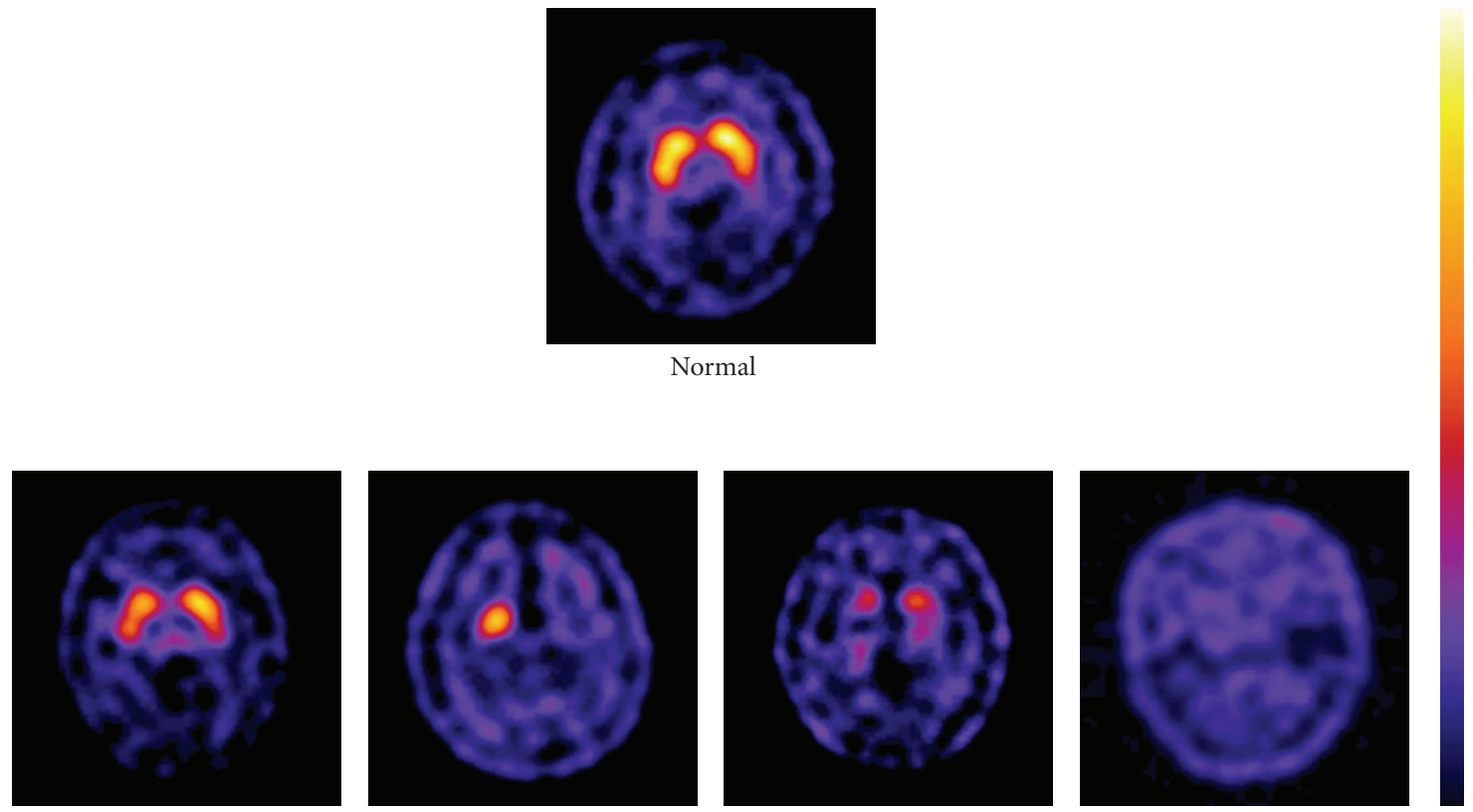

Parkinson's disease

FIgURE 1: ${ }^{99 m}$ Tc-TRODAT-1 imaging on four patients with Parkinson's disease at different stage and one normal control. The differentiation between normal and PD is primarily based on shape that reflects differences of uptake intensity.

enzyme responsible for the conversion of ${ }^{18} \mathrm{~F}-\mathrm{FDOPA}$ to ${ }^{18} \mathrm{~F}$-dopamine $[3,10]$. Therefore, particularly in the early stages of disease, ${ }^{18} \mathrm{~F}$-FDOPA PET may underestimate the degenerative process, due to the compensatory upregulation of AADC in the remaining terminals. Moreover, because AADC is present in the terminals of all monoaminergic neurons, measurements of ${ }^{18} \mathrm{~F}$-FDOPA uptake into extrastriatal areas provide an index of the density of the serotonergic, noradrenergic, and dopaminergic terminals $[3,10]$.

DAT is a protein complex located in presynaptic dopaminergic nerve terminals, which serves as the primary means for removing monoaminergic neurotransmitters from the synaptic cleft. It is therefore a potential marker of the integrity of nigrostriatal projections. Several PET ligands $\left({ }^{11} \mathrm{C}-\mathrm{CFT},{ }^{18} \mathrm{~F}-\mathrm{CFT},{ }^{18} \mathrm{~F}\right.$-FP-CIT, and $\left.{ }^{11} \mathrm{C}-\mathrm{PE} 2 \mathrm{I}\right)$ and SPECT tracers $\left({ }^{123} \mathrm{I}-\beta\right.$-CIT, ${ }^{123} \mathrm{I}$-FP-CIT, ${ }^{123} \mathrm{I}$-altropane, ${ }^{123} \mathrm{I}$-PE2I, and ${ }^{99 \mathrm{~m}}$ Tc-TRODAT- 1 ) are now available to measure DAT availability $[10,11]$. The technetium-based ${ }^{99 \mathrm{~m}}$ Tc-TRODAT1 has the advantage of being relatively inexpensive and available in kit form [12]. However, its specific signal is lower than the ${ }^{123}$ I-based SPECT tracers. In general, all the DAT markers have shown efficacy in PD similar to that achieved with ${ }^{18} \mathrm{~F}$-FDOPA PET; all are able to differentiate patients with early PD from healthy subjects with a sensitivity and specificity of approximately $90 \%$ [1315]. A multicenter, phase III trial conducted at Institute of Nuclear Energy Research (INER) indicated that patients with PD were easily distinguished from healthy volunteers with the ${ }^{99 \mathrm{~m}}$ Tc-TRODAT-1 SPECT, which had a sensitivity of $97.2 \%$ and a specificity of $92.6 \%$ (unpublished data). Figure 1 depicts the typical dopamine transporter images in
4 patients with PD for different stage and a healthy control. The differentiation between normal and Parkinson's disease is primarily based on shape, which reflects differences of uptake intensity. The high sensitivity and specificity of DAT images make them useful in both the clinical diagnosis of $\mathrm{PD}$ and preclinical screening for asymptomatic individuals. To date, only DaTSCAN ( ${ }^{123} \mathrm{I}$-FP-CIT) and ${ }^{99 \mathrm{~m}} \mathrm{Tc}$-TRODAT1 are available on the market and licensed for detecting loss of functional dopaminergic neuron terminals in the striatum. In contrast to ${ }^{18} \mathrm{~F}$-FDOPA, the striatal uptake of DAT ligands in early PD may overestimate the reduction in terminal density due to the relative downregulation of DAT in the remaining neurons as a response to nigral neuron loss; this is a compensatory mechanism that acts to maintain synaptic dopamine levels. DAT binding falls with age in healthy subjects, but striatal ${ }^{18} \mathrm{~F}$-FDOPA uptake does not appear to be age dependent $[3,12,16]$.

Dopaminergic neurotransmission plays an important role in regulating several aspects of basic brain function, including motor behavior, motivation, and working memory. Dopaminergic systems are also a central element in the brain reward system that controls learning. There are five subtypes of dopamine receptors, $\mathrm{D}_{1}, \mathrm{D}_{2}, \mathrm{D}_{3}, \mathrm{D}_{4}$, and $D_{5} . D_{1}$ and $D_{5}$ receptors are members of the $D_{1}$ like family of dopamine receptors, and $\mathrm{D}_{2}, \mathrm{D}_{3}$, and $\mathrm{D}_{4}$ receptors are members of the $\mathrm{D}_{2}$-like family. The assessment of $\mathrm{D}_{1}$-like receptors has not achieved clinical significance; therefore, in the past, many investigations have focused on the $\mathrm{D}_{2}$-like receptor system. Positron-emitting ligands, like ${ }^{11} \mathrm{C}$-raclopride, ${ }^{18} \mathrm{~F}$-spiperone, and ${ }^{18} \mathrm{~F}$-methyl-benperidol have been developed for the visualization of dopamine 
$\mathrm{D}_{2}$ receptors in vivo with PET; alternatively, single-proton emitting ligands, like ${ }^{123}$ I-iodobenzamide $\left({ }^{123} \mathrm{I}\right.$-IBZM), ${ }^{123} \mathrm{I}-$ epidrpride, and ${ }^{123} \mathrm{I}-\mathrm{IBF}$ have been developed for SPECT imaging. ${ }^{11} \mathrm{C}$-raclopride, a derivative of benzamide, is currently the gold standard PET tracer for $\mathrm{D}_{2}$ receptors [17].

It is important to discriminate between idiopathic Parkinson's disease (IPD) and other neurodegenerative parkinsonian syndromes (non-IPS), because there are marked differences in the prognoses and therapies. DAT imaging with ${ }^{99 \mathrm{~m}} \mathrm{Tc}$-TRODAT-1 SPECT has proven successful in the differential diagnosis between PD and vascular parkinsonism; patients with PD displayed a significant decrease in striatal ${ }^{99 \mathrm{~m}} \mathrm{Tc}$-TRODAT-1 uptake compared to patients with vascular parkinsonism $(P<.01)$ [18]. Higher diagnostic accuracy in the differential diagnosis of parkinsonism may be achieved by combining pre- and postsynaptic quantitative information about the dopaminergic system. Previous imaging studies with the most commonly used dopamine $\mathrm{D}_{2}$ receptor tracers, ${ }^{11} \mathrm{C}$-raclopride and ${ }^{123} \mathrm{I}$ IBZM, have consistently shown that DATs, which represent the integrity of the nigrostriatal neurons, are downregulated in patients with early IPD, but $\mathrm{D}_{2}$ receptors are normal or even upregulated. In contrast, patients with multiple system atrophy (MSA) typically show reductions in both DAT and $\mathrm{D}_{2}$ binding $[19,20]$. However, with progression of $\mathrm{PD}$, striatal $\mathrm{D}_{2}$ receptor activity returns to normal or may fall below normal levels [2], and the small differences in $\mathrm{D}_{2}$ binding make it difficult to distinguish between PD, IPD, and healthy control groups (unpublished data).

Gradually, we have attained a broader understanding of the genetic linkages among different aspects of parkinsonism. Approximately $20 \%$ of patients with PD have genetic mutations [21]. Several genes, including PINK1, SNCA, parkin, UCHL1, DJ1, and LRRK2, have been associated with familial parkinsonism and/or sporadic early onset Parkinson's disease (EOPD). A ${ }^{99 \mathrm{~m}} \mathrm{Tc}-\mathrm{TRODAT}-1$ scan showed that patients with the PINK1 mutation displayed a rather even, symmetrical reduction of dopamine uptake; in contrast, patients with late-onset Parkinson's disease (LOPD) displayed a dominant decline in dopamine uptake in the putamen [22]. In addition, ${ }^{99 \mathrm{~m}} \mathrm{Tc}-\mathrm{TRODAT}-1$ SPECT revealed that the dopamine transporter concentration was significantly reduced in patients with Machado-Joseph Disease and in asymptomatic gene carriers compared to healthy volunteers $(P<.001)$. This indicated that the brain SPECT was capable of detecting early alterations in dopamine neurons of the striatal region [23].

Molecular imaging is also a major tool for the evaluation of new experimental therapeutic strategies in PD, particularly for those that aim to restore or protect striatal dopaminergic innervation. Neuroprotective and diseasemodifying drug research has intensified, and the results rely heavily on accurate early diagnosis [24]. Several teams of investigators have reported the results from double-blind, placebo-controlled trials of human embryonic dopaminergic tissue transplantation for the treatment of PD. Evaluations with ${ }^{18} \mathrm{~F}-\mathrm{FDOPA}$ scans have shown that significant declines in the motor scores over time after transplantation $(P<.001)$, based on the Unified Parkinson Disease Rating Scale (UPDRS), were associated with increases in putamen ${ }^{18} \mathrm{~F}$-FDOPA uptake at 4 -year posttransplantation followups $(P<.001)$. Furthermore, posttransplantation changes in putamen PET signals and clinical outcomes were significantly intercorrelated $(P<.02)[25,26]$. Current imaging biomarkers may be a valuable adjunct to clinical data for assessing both the mechanism and efficacy of neuroprotective agents. To date, functional imaging studies in these trials have failed to demonstrate a clear-cut neuroprotective effect on nigrostriatal degeneration. In addition, discordance between clinical and imaging outcomes has been reported in studies that compared a dopamine agonist versus levodopa [10,27].

Gene therapy may be potentially useful for ameliorating the motor symptoms of PD and the motor complications of PD treatments. Several gene therapy studies in humans investigated transductions (with various viral vectors) of glialderived neurotrophic factor (GDNF), neurturin (NTN), AADC, or glutamic acid decarboxylase (GAD) [28]. Brain imaging with ${ }^{18} \mathrm{~F}$-FDODA PET, ${ }^{18} \mathrm{~F}$-FFMT, or ${ }^{18} \mathrm{~F}$-FDG PET was used to evaluate clinical outcomes adjunct to the UPDRS scores [29-33].

\section{Alzheimer's Disease}

Alzheimer's disease (AD) is the most common form of dementia. $\mathrm{AD}$ is characterized by progressive impairments in cognitive function and behavior [34]. Data suggest that the number of patients with $\mathrm{AD}$ worldwide will increase from 26.6 million in 2006 to 106.8 million in 2050 [35, 36]. Beta amyloid (A $\beta$ 1-42) is considered a primary cause of $\mathrm{AD}$, but there are numerous other ongoing processes, including oxidative stress, inflammatory reactions, microglial activation, tau phosphorylation, and neurotransmitter impairments, that can lead to cognitive impairments $[36,37]$. Some methods have shown promise as diagnostic tools for $\mathrm{AD}$, including MRI measurements of medial temporal lobe atrophy, PET imaging of glucose metabolism and $\mathrm{A} \beta$ deposits, and cerebral spinal fluid (CSF) biomarkers. A substantial number of studies have shown that MRI measurements of hippocampal atrophy can distinguish between subjects with $\mathrm{AD}$ and older subjects with normal cognition with $80-90 \%$ accuracy $[34,38]$.

PET tracers have been developed for studies of functional activity, neurotransmitter activity, and pathologic processes in different dementia disorders. PET imaging with ${ }^{18} \mathrm{~F}$-FDG has shown that $\mathrm{AD}$ was associated with metabolic deficits in the neocortical association areas, but normal activity was observed in the basal ganglia, thalamus, cerebellum, primary sensory motor cortex, and visual cortex [39]. During disease progression, glucose metabolism continues to decline, and this is associated with declining scores on cognitive tests [40]. A large multicenter study showed $93 \%$ sensitivity and specificity for distinguishing between individuals with $\mathrm{AD}$ and normal individuals [34]. This indicated that ${ }^{18} \mathrm{~F}-\mathrm{FDG}$ PET can serve as a biomarker in clinical trials [36].

Imaging techniques that include radiolabeled PET tracers that can bind to aggregated $A \beta$ peptides in $A \beta$ plaques have 
the potential of directly assessing relative brain $A \beta$ plaque pathology. Several research groups have applied the smallmolecule approach to the development of tracers suitable for amyloid imaging; for example, derivatives of Congo red, thioflavin, stilbene, chrysamine-G, and acridine were developed for PET and SPECT imaging. This opens up new possibilities for early diagnosis and provides new tools for monitoring antiamyloid therapy in $\mathrm{AD}[36,41-44]$.

${ }^{18} \mathrm{~F}$-FDDNP was the first PET tracer used in vivo for detecting cerebral amyloid plaques. Increased ${ }^{18} \mathrm{~F}$-FDDNP binding was observed in the temporal, parietal, and frontal regions of the $\mathrm{AD}$ brain, compared with brains from older control subjects with no cognitive impairments. ${ }^{18} \mathrm{~F}$-FDDNP binds to both neuritic plaques and neurofibrillary tangles [45]. Pittsburgh compound B $\left({ }^{11} \mathrm{C}-\mathrm{PIB}\right)$, a derivative of thioflavin- $\mathrm{T}$, binds with high affinity and high specificity to neuritic $\mathrm{A} \beta$ plaques, but it shows no binding to diffuse plaques or neurofibrillary tangles [46]. ${ }^{11} \mathrm{C}-\mathrm{PIB}$ PET is presently the most used amyloid PET ligand; it has been studied in over 2000 subjects $[39,40]$. Imaging with ${ }^{11} \mathrm{C}$ PIB PET showed significantly higher retention in the frontal, temporal, parietal, and occipital cortices and the striatum of patients with $\mathrm{AD}$ compared to healthy controls (1.9to 1.5 -fold differences). Interestingly, the increase in ${ }^{11} \mathrm{C}$ PIB retention observed in mild $\mathrm{AD}$ patients relative to agematched healthy controls was larger than the decrease in ${ }^{18} \mathrm{~F}$ FDG uptake in $\mathrm{AD}$ patients relative to controls [47]. Figure 2 illustrates cerebral glucose metabolism as assessed by ${ }^{18} \mathrm{~F}$ FDG PET and amyloid plaque burden as assessed by ${ }^{11} \mathrm{C}-\mathrm{PIB}$ PET in two AD patients and a healthy control [43].

The memory predominant subtype, amnestic mild cognitive impairment (MCI), has been suggested to constitute a transitional stage between normal aging and $\mathrm{AD}$ [34]. Clinical studies suggested that about $12 \%$ of patients with the amnestic form of MCI progressed to $\mathrm{AD}$ within one year and up to $80 \%$ progressed to $\mathrm{AD}$ after 6 y [48]. Glucose metabolism is a sensitive measure of change in cognition and functional ability, both in $\mathrm{AD}$ and in MCI; therefore, accurate detection of changes in glucose metabolism has value in predicting future cognitive decline [49]. Clinical follow-up studies have shown that patients with MCI who converted to $\mathrm{AD}$ showed significantly higher ${ }^{11} \mathrm{C}$-PIB retention than those with $\mathrm{MCI}$ that did not convert; this suggested the possibility of identifying prodromal $\mathrm{AD}$ with $\beta$-amyloid imaging [36, 50].

To date, ${ }^{11} \mathrm{C}$-PIB PET is the most widely used imaging approach for the visualization of $\mathrm{A} \beta$. Although ${ }^{11} \mathrm{C}$-PIB can be used for academic studies, the 20-minute half-life of ${ }^{11} \mathrm{C}$ and limited manufacturing access makes the molecule unsuitable for widespread use as a routine diagnostic agent. ${ }^{18} \mathrm{~F}$, with a half-life of 110 minutes, offers much better potential for manufacturing and distribution. In addition to ${ }^{18} \mathrm{~F}$-FDDNP, several ${ }^{18} \mathrm{~F}$-labeled $\mathrm{A} \beta$ tracers have been successfully investigated in clinical trials, including ${ }^{18} \mathrm{~F}-\mathrm{PIB}\left({ }^{18} \mathrm{~F}-\right.$ flutemetamol), ${ }^{18} \mathrm{~F}-\mathrm{AV}-1$ ( $\left({ }^{18} \mathrm{~F}-\mathrm{BAY} 94-9172\right)$, and ${ }^{18} \mathrm{~F}-\mathrm{AV}-45$ (Florbetapir F-18). ${ }^{18} \mathrm{~F}-\mathrm{AV}-45$, a derivative of stilbene, has demonstrated high binding to the $A \beta$ aggregates in patients with $\mathrm{AD}$. In a pilot study, patients with $\mathrm{AD}$ and healthy controls displayed averages of $1.67 \pm 0.18$ and $1.25 \pm 0.18$, respectively, in standard uptake value ratios (SUVRs) of ${ }^{18} \mathrm{~F}$ AV-45 for the cortical area relative to the cerebellum [51]. The interim results of a phase III study demonstrated that the ${ }^{18} \mathrm{~F}-\mathrm{AV}-45$ PET images correlated strongly with the postmortem histopathology findings. The PET images correctly identified subjects that had $\beta$-amyloid deposits and showed where in the brain the deposits had accumulated. Recently, a marketing application for Florbetapir was submitted to the FDA.

In the regions of the highest retention, the specific signal from ${ }^{18} \mathrm{~F}$-FDDNP was only 0.3 times that of the reference tissue; this contrasts with the 1.5-2.0-fold specific signal with respect to the reference tissue that was associated with the ${ }^{11} \mathrm{C}$-PIB [47] and ${ }^{11} \mathrm{C}$-SB13 tracers [52]. Visual assessment of ${ }^{11} \mathrm{C}$-PIB PET images demonstrated promise as a supportive diagnostic marker for $\mathrm{AD}$ with both sensitivity and specificity values of 0.95 . Additionally, ${ }^{18} \mathrm{~F}$-PIB showed promise as an $\mathrm{AD}$ biomarker with both sensitivity and specificity values of 0.93 ; in contrast, ${ }^{18} \mathrm{~F}$-FDDNP PET images showed only moderate accuracy, with a sensitivity of 0.81 and a specificity of $0.72[53,54]$.

Development of amyloid probes applicable to both PET and SPECT in AD may provide a cost-effective approach, particularly when effective antiamyloid therapy becomes available. Accurate and early diagnoses of dementias will become increasingly important as new therapies are introduced. The presently available imaging ligands will be valuable for monitoring any reduction in $\mathrm{A} \beta$ plaques. Ongoing studies with antiamyloid therapies, including a vaccination, an $\mathrm{A} \beta$ fibrillization inhibitor, or a secretase modulator, have described some difficulties in the assessment of drug effects at autopsy. Assessments of the efficacy of antiamyloid therapy could be greatly facilitated with the visualization of amyloid plaques in the brains of living patients with $\mathrm{AD}$ [55].

One hypothesis holds that there is a cholinergic mechanism underlying $\mathrm{AD}$; this hypothesis proposes that degeneration of cholinergic neurons in the basal forebrain nuclei causes disturbances in presynaptic cholinergic terminals in the hippocampus and neocortex, which are important for memory disturbances and other cognitive symptoms [34]. The most important degrading enzyme for acetylcholine in the human cortex is acetylcholinesterase, which is present in cholinergic axons. The PET tracers, ${ }^{11} \mathrm{C}-\mathrm{PMP}$ and ${ }^{11} \mathrm{C}-$ MP4A, have been used to measure acetylcholinesterase activity. These tracers showed a decline in acetylcholinesterase activity in patients with $\mathrm{AD}$ compared to healthy controls. Reduction in acetylcholinesterase activity has also been reported in patients with MCI, particularly in those that later converted to $\mathrm{AD}$. This suggested that acetylcholinesterase changes might precede the development of clinical $\mathrm{AD}$ [56]. The inhibition of acetylcholinesterase with specific therapeutic drugs, like donepezil, can also be measured with these tracers [57].

\section{Affective Disorders}

Serotonin (5-hydroxy-tryptamine, 5-HT) is a modulatory neurotransmitter in the human brain that regulates mood, 


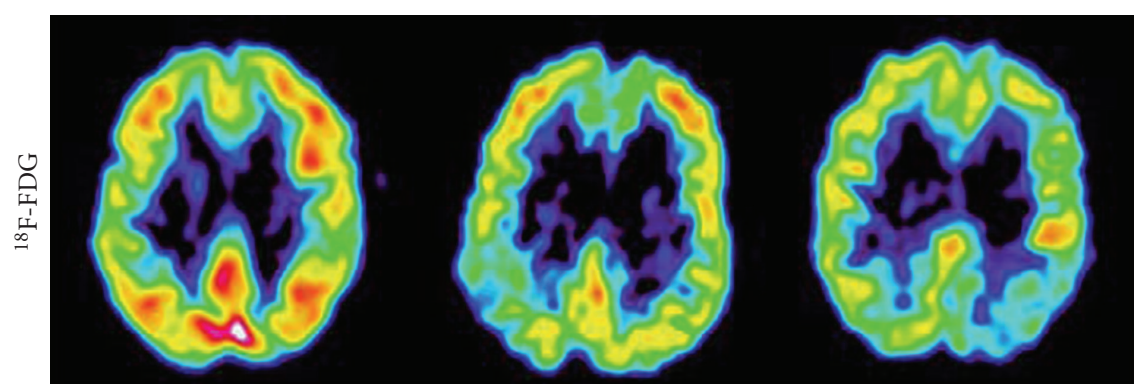

(a)

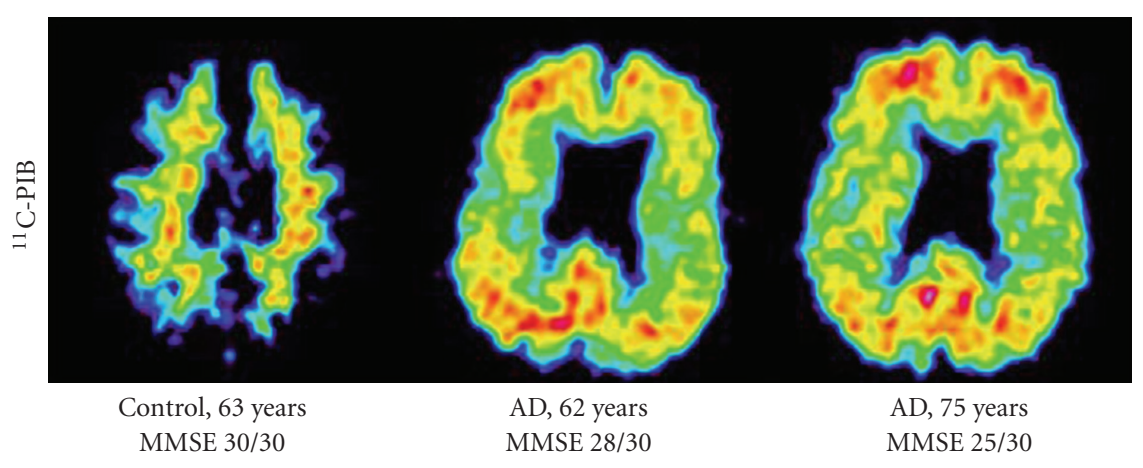

(b)

Figure 2: Cerebral glucose metabolism $\left({ }^{18} \mathrm{~F}-\mathrm{FDG}\right)$ and ${ }^{11} \mathrm{C}-\mathrm{PIB}$ amyloid imaging in two AD patients and one healthy control. The PET scans show ${ }^{18} \mathrm{~F}-\mathrm{FDG}$ and ${ }^{11} \mathrm{C}-\mathrm{PIB}$ at a sagittal section. MMSE: Mini Mental State Examination. Adapted from [43].

anger, reward, aggression, and appetite [58]. Serotonergic neurotransmission is altered in many neuropsychiatric disorders, including depression, anxiety disorders, biopolar disorders (BD), compulsive disorders, autism, schizophrenia, $\mathrm{AD}$, and $\mathrm{PD}[2,59]$.

There is broad heterogeneity in the postsynaptic serotonin receptors; however, the only suitable radioligands available are for $5-\mathrm{HT}_{1 \mathrm{~A}}$ and $5-\mathrm{HT}_{2 \mathrm{~A}}$ receptors [2]. For visualization of brain $5-\mathrm{HT}_{1 \mathrm{~A}}$ receptor activity, the ${ }^{11} \mathrm{C}$ WAY-100635 (WAY) and ${ }^{18} \mathrm{~F}-$ labeled analogs of WAY $\left({ }^{18} \mathrm{~F}-\right.$ trans-FCWAY) exhibited high affinity. $5-\mathrm{HT}_{1 \mathrm{~A}}$ receptors are present in high density in the hippocampus, septum, amygdala, hypothalamus, and neocortex of the human brain. PET imaging with ${ }^{18} \mathrm{~F}$-FCWAY demonstrated that abnormalities of $5-\mathrm{HT}_{1 \mathrm{~A}}$ receptors were present in affective disorders, particularly in depression and panic disorder [6062]. However, there were only small differences between the study population and the healthy control groups; this may indicate considerable overlap between groups, which would impede a clear diagnostic cutoff. $5-\mathrm{HT}_{2 \mathrm{~A}}$ receptors are present in all neocortical regions, with lower densities in the hippocampus, basal ganglia, and thalamus. $5-\mathrm{HT}_{2 \mathrm{~A}}$ receptors have been quantified with ${ }^{18} \mathrm{~F}$-altanserin, ${ }^{18} \mathrm{~F}$-setoperone, and ${ }^{123} \mathrm{I}$-2-ketanserin [58]. ${ }^{18} \mathrm{~F}$-setoperone showed specific binding in the cortex, reversibility, and a favorable ratio of specific binding to nonspecific binding and unbound label [63]. PET studies with ${ }^{18} \mathrm{~F}$-Setoperone showed significantly decreased $5-\mathrm{HT}_{2 \mathrm{~A}}$ receptor densities in neuroleptic-naïve patients with schizophrenia and in patients with $\mathrm{AD}[64,65]$.
The serotonin transporter (SERT, 5-HTT) plays an important role in modulating presynaptic serotonergic function. It removes serotonin from the synaptic cleft and terminates its function [66]. SERT is the primary target for selective serotonin reuptake inhibitors (SSRIs), which are commonly used for treatment of psychiatric disorders, and as the first-line treatment for major depression and anxiety disorders. SERT imaging provides information on the integrity of serotonergic neurotransmission in vivo. ${ }^{123} \mathrm{I}-$ $\beta$-CIT was the first SERT marker to be applied; however, it binds all the monoamine transporters, including SERT, DAT, and norepinephrine transporters (NETs). The first PET radiotracer that was selective for brain SERT was ${ }^{11}$ C-McN5652 [67, 68]. Subsequently, two excellent PET tracers were developed for visualization of SERT in human brains; these are known as ${ }^{11} \mathrm{C}-\mathrm{DASB}$ and ${ }^{11} \mathrm{C}-\mathrm{MADAM}$, and both exhibit high affinity and selectivity for SERT [69]. Alternatively, a promising SPECT tracer was also developed for visualization of SERT in humans; this ${ }^{123} \mathrm{I}$ ADAM, a derivative of 403U76, displays high affinity and selectivity for SERT. ${ }^{123}$ I-ADAM was efficiently taken up in the hypothalamus, brain stem, pons, and medial temporal lobe [70]. Compared with previous radioligands, ${ }^{11} \mathrm{C}$-DASB offers both high selectivity and a favorable ratio of specific binding relative to free and nonspecific binding. Therefore, ${ }^{11} \mathrm{C}$-DASB PET imaging is considered as the state-of-the-art method for quantifying SERT in humans.

In vivo imaging studies of SERT have generally been conducted in patients with acute depression; however, the 
results have been somewhat inconsistent [71]. Parsey et al. used ${ }^{11} \mathrm{C}-\mathrm{McN} 5652$ PET in unmedicated patients with major depression. Those patients had lower SERT binding potential in the amygdala and midbrain region compared to healthy subjects [72]. In a study with ${ }^{11} \mathrm{C}$-DASB PET, brain SERT density was investigated in subjects with a history of major depressive episodes (MDEs). Those patients displayed no regional differences in SERT binding potential compared to healthy subjects $[73,74]$. Newberg et al. used ${ }^{123}$ I-ADAM SPECT and found reduced SERT binding potential in the midbrain regions of patients with depression compared to healthy volunteers [75]; however another study with ${ }^{123} \mathrm{I}-$ ADAM SPECT found no difference between similar groups [76]. Dysfunction in serotonin neurotransmission is likely to play a critical role in $\mathrm{BD}$ [77]. BD is defined on the basis of manic symptoms of varying severity. Bipolar I disorder (BD I) is defined by a full-blown episode of mania, whereas bipolar II disorder (BD II) is defined by hypomanic episodes and depressive episodes [78]. Assessment of SERT binding in the midbrain with ${ }^{123} \mathrm{I}$-ADAM SPECT demonstrated no differences in brain SERT binding between healthy controls and patients with $\mathrm{BD}$ that were in a euthymic state. However, the SERT binding was lower in patients with BD I compared to those with BD II. Furthermore, the decreased specific uptake ratios (SURs) in BD I patients were well correlated with the duration of the illness $(R=-0.742, P=.014)$ [79]. In addition to the serotonin system, the DAT gene was also shown to play a role in the etiology of both adult and pediatric BD. Using ${ }^{99 \mathrm{~m}} \mathrm{Tc}$-TRODAT-1 SPECT, Chang et al. found that striatal DAT availability was significantly higher in patients with euthymic BD than in healthy volunteers [80].

Aggression is one of the most extensively studied areas of human behavior. Central serotoninergic function has been linked to both normal and pathological aggressiveness. Because hostility shares some similarities with aggression, it is possible that central serotonin activity is also related to hostility. ${ }^{123}$ I-ADAM SPECT imaging indicates that central serotoninergic activities may play a role in hostility. The hostile attribution subscore was negatively correlated with SERT availability $(r=-0.71, P<.05)[81]$.

Although imaging of the serotonin system has many potential clinical uses, currently, serotonin imaging is not used for the routine diagnosis of any neuropsychiatric diseases. Perhaps one of the most valuable current uses of molecular imaging technology is the determination of the in vivo brain occupancy of a putative pharmaceutical at the target of interest when developing a pharmaceutical treatment for depression. Currently, there is no other method available for in vivo determinations of receptor occupancy in humans [58]. Drug concentrations in plasma may vary by over tenfold when identical doses are administered to different patients. Therapeutic drug monitoring can reduce the number of nonresponders and decrease the risk for developing side effects by identifying patients with either insufficient or excess serum concentrations of the drug [82]. The first SSRI occupancy study with ${ }^{11}$ C-DASB PET found $80 \%$ striatal occupancy in multiple regions after 4 weeks of antidepressant treatment, with doses of paroxetine and citalopram known to have clinical effects distinct from

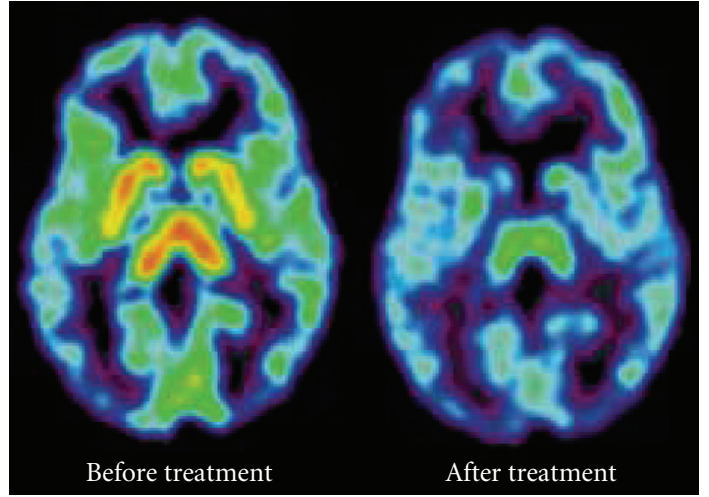

(a)

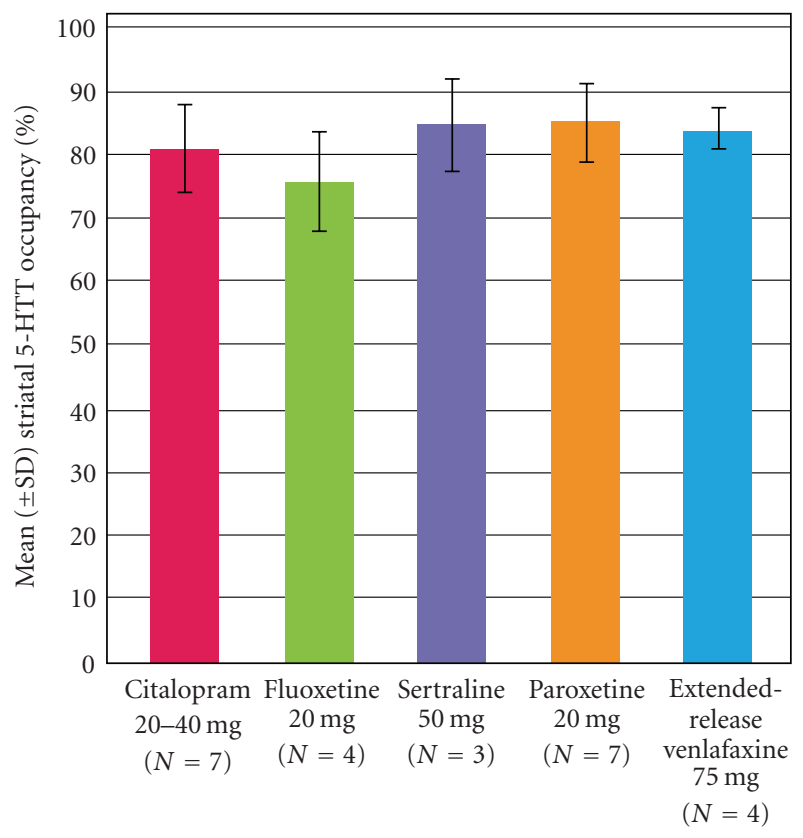

SSRI and minimum therapeutic dose

(b)

Figure 3: (a) Effect of citalopram on ${ }^{11} \mathrm{C}$-DASB PET scan of the serotonin transporter in a depressed subject. Treatment was with $20 \mathrm{mg} /$ day of citalopram for 4 weeks. Adapted from [73]. (b) Striatal serotonin transporter (5-HTT) occupancy in depressed subjects after 4 weeks of treatment at minimum therapeutic doses of five SSRIs. Adapted from [74].

placebo [73]. Thereafter, occupancy measurements of citalopram, fluoxetine, sertraline, paroxetine, or venlafaxine with ${ }^{11}$ C-DASB PET suggested that $80 \%$ occupancy of the SERT was a necessary minimum for SSRI efficacy for depressive episodes. Moreover, occupancy increased as the dose or plasma level increased, and occupancy reached a plateau at saturating doses [74]. Figure 3(a) illustrates a typical occupancy study of citalopram on the serotonin transporters with ${ }^{11}$ C-DASB PET scan in a depressed subject [73]. Figure 3(b) summaries the striatal SERT occupancy in depressed subjects after 4 weeks of treatment at minimum therapeutic doses of five SSRIs [74]. Given the association between the clinically 
relevant dose and SERT occupancy for all SSRIs, it is now generally believed that an $80 \%$ SERT occupancy with an SSRI is therapeutically useful. Consequently, antidepressant drug development aims for $80 \%$ serotonin transporter occupancy. This practical approach can be applied in phase I trials to assess whether potential new antidepressant drugs can adequately penetrate the brain and in phase II clinical trials to guide dosing selections [69].

NETs are responsible for the reuptake of norepinephrine into presynaptic nerves, and they are a primary target of antidepressants. With the development of NET tracers, like ${ }^{18} \mathrm{~F}-\mathrm{FMeNER}-\mathrm{D}_{2}$ [83] and ${ }^{11} \mathrm{C}-\mathrm{MRB}$ [84], it is currently possible to investigate NET occupancy for antidepressants that are selective norepinephrine reuptake inhibitors (SNRIs). In an investigation with ${ }^{18} \mathrm{~F}-\mathrm{FMeNER}-\mathrm{D}_{2}$, the NET occupancy of nortriptyline was $16 \%$ to $41 \%$, which corresponded to a dose of $10-75 \mathrm{mg}$ [83]. In addition to NET, antidepressants also target DAT. Bupropion is thought to exert its antidepressive effect by blocking the DAT and NET with an efficacy comparable to that of SSRIs. With bupropion treatment, the average DAT occupancy was $20.84 \%$, measured by ${ }^{99 \mathrm{~m}} \mathrm{Tc}$ TRODAT-1 SPECT [85]. To achieve SNRI efficacy, the optimal and minimal occupancies of NET remain to be determined.

For antipsychotic drugs, it was shown that the occupancy of dopamine $\mathrm{D}_{2}$-like receptors was better correlated to plasma concentrations than to the doses administered [82]. In association with the analysis of clinical effects, Farde et al. established the concept that at least $60-70 \%$ dopamine receptor occupancy was necessary for treating positive symptoms of schizophrenia. However, occupancies above $80 \%$ were associated with extrapyramidal side effects $[82,86]$.

\section{Conclusions and Future Directions}

With the appropriate radioligands, molecular imaging enables the visualization of presynaptic and postsynaptic sites in the dopaminergic system. This can provide crucial information for the assessment and monitoring of neuroprotective agents, gene therapies, and stem cell strategies for the treatment of PD. Future studies are needed in the development of new radiotracers to target nondopaminergic brain pathways and the glial reaction to disease.

Accurate and early differentiation of dementias will become increasingly important as new therapies are introduced. Recently, reliable PET tracers for assessing the A $\beta$ burden in the brain have been introduced; these tracers may be valuable for early diagnosis of the presymptomatic stages of $\mathrm{AD}$. The measurement of $\beta$-amyloid in vivo will greatly facilitate our understanding of the underlying pathophysiological mechanisms of $\mathrm{AD}$; in addition, these measurements will promote the testing of new antiamyloid drugs and therapies. Although early studies were performed with ${ }^{11} \mathrm{C}-\mathrm{PIB}$, several groups have developed fluorinated compounds for widespread and routine diagnostic uses.

Although serotonin imaging has many potential clinical applications, currently, serotonin imaging is not used for the routine diagnosis of any neuropsychiatric diseases. Perhaps one of the most valuable current uses of molecular imaging technology is the determination of in vivo brain occupancy of a putative pharmaceutical agent when developing a treatment for depression. Finally, to achieve SNRI efficacy, the optimal and minimal occupancies of NET remain to be determined.

In the future, the role of molecular imaging may become more significant in guiding therapy. Enhancements in image resolution and specific molecular tags will permit accurate diagnoses of a wide range of diseases, based on both structural and molecular changes in the brain. For widespread application, advances in molecular imaging should include the characterization of new radiotracers, application of modeling techniques, standardization and automation of image-processing techniques, and appropriate clinical settings in large multicenter trials. The growing field of molecular imaging is helping nuclear medicine physicians identify pathways into personalized patient care.

\section{Acknowledgments}

The authors are indebted to the research teams of Chang Gung Memorial Hospital, Tri-Service General Hospital, National Cheng Kung University Hospital, and Taipei Veterans General Hospital for carrying out the clinical studies for the neuroimaging agents developed at Institute of Nuclear Energy Research. The development of neuroimaging agents was partially supported by the grant from National Science Council (NSC99-3111-Y-042A-013).

\section{References}

[1] M. Fumita and R. B. Innis, "In vivo molecular imaging: ligand development and research applications," in Neuropsychopharmacology: The Fifth Generation of Progress, pp. 411-425, 2000.

[2] W. D. Heiss and K. Herholz, "Brain receptor imaging," Journal of Nuclear Medicine, vol. 47, no. 2, pp. 302-312, 2006.

[3] N. Pavese, L. Kiferle, and P. Piccini, "Neuroprotection and imaging studies in Parkinson's disease," Parkinsonism and Related Disorders, vol. 15, no. 4, pp. S33-S37, 2010.

[4] D. J. Gelb, E. Oliver, and S. Gilman, "Diagnostic criteria for Parkinson disease," Archives of Neurology, vol. 56, no. 1, pp. 33-39, 1999.

[5] E. Tolosa, G. Wenning, and W. Poewe, "The diagnosis of Parkinson's disease," Lancet Neurology, vol. 5, no. 1, pp. 75-86, 2006.

[6] A. J. Hughes, S. E. Daniel, S. Blankson, and A. J. Lees, "A clinicopathologic study of 100 cases of Parkinson's disease," Archives of Neurology, vol. 50, no. 2, pp. 140-148, 1993.

[7] A. H. Rajput, B. Rozdilsky, and A. Rajput, "Accuracy of clinical diagnosis in Parkinsonism-a prospective study," Canadian Journal of Neurological Sciences, vol. 18, no. 3, pp. 275-278, 1991.

[8] C. Sioka, A. Fotopoulos, and A. P. Kyritsis, "Recent advances in PET imaging for evaluation of Parkinson's disease," European Journal of Nuclear Medicine and Molecular Imaging, vol. 37, pp. 1594-1603, 2010.

[9] D. J. Brooks, K. A. Frey, K. L. Marek et al., "Assessment of neuroimaging techniques as biomarkers of the progression of 
Parkinson's disease," Experimental Neurology, vol. 184, no. 1, pp. S68-S79, 2003.

[10] N. Pavese and D. J. Brooks, "Imaging neurodegeneration in Parkinson's disease," Biochimica et Biophysica Acta, vol. 1792, no. 7, pp. 722-729, 2009.

[11] M. J. Ribeiro, M. Vidailhet, C. Loc'h et al., "Dopaminergic function and dopamine transporter binding assessed with positron emission tomography in Parkinson disease," Archives of Neurology, vol. 59, no. 4, pp. 580-586, 2002.

[12] S. K. Meegalla, K. Plössl, M. P. Kung et al., "Synthesis and characterization of technetium-99m-labeled tropanes as dopamine transporter-imaging agents," Journal of Medicinal Chemistry, vol. 40, no. 1, pp. 9-17, 1997.

[13] P. D. Mozley, J. S. Schneider, P. D. Acton et al., "Binding of $\left[{ }^{99 \mathrm{~m}} \mathrm{Tc}\right]$ TRODAT-1 to dopamine transporters in patients with Parkinson's disease and in healthy volunteers," Journal of Nuclear Medicine, vol. 41, no. 4, pp. 584-589, 2000.

[14] W. S. Huang, Y. H. Chiang, J. C. Lin, Y. H. Chou, C. Y. Cheng, and R. S. Liu, "Crossover study of ${ }^{99 \mathrm{~m} T c-T R O D A T-1}$ SPECT and ${ }^{18}$ F-FDOPA PET in Parkinson's disease patients," Journal of Nuclear Medicine, vol. 44, no. 7, pp. 999-1005, 2003.

[15] Y. H. Weng, T. C. Yen, M. C. Chen et al., "Sensitivity and specificity of ${ }^{99 \mathrm{~m}}$ Tc-TRODAT-1 SPECT imaging in differentiating patients with idiopathic Parkinson's disease from healthy subjects," Journal of Nuclear Medicine, vol. 45, no. 3, pp. 393401, 2004.

[16] E. Nurmi, H. M. Ruottinen, J. Bergman et al., "Rate of progression in Parkinson's disease: a $6-\left[{ }^{18} \mathrm{~F}\right]$ fluoro-L-dopa PET study," Movement Disorders, vol. 16, no. 4, pp. 608-615, 2001.

[17] L. Farde, S. Pauli, H. Hall et al., "Stereoselective binding of 11C-raclopride in living human brain - A search for extrastriatal central D2-dopamine receptors by PET," Psychopharmacology, vol. 94, no. 4, pp. 471-478, 1988.

[18] K. Y. Tzen, C. S. Lu, T. C. Yen, S. P. Wey, and G. Ting, "Differential diagnosis of Parkinson's disease and vascular parkinsonism by [ $\left.{ }^{99 \mathrm{~m}} \mathrm{Tc}\right]-$ TRODAT-1," Journal of Nuclear Medicine, vol. 42, no. 3, pp. 408-413, 2001.

[19] W. Koch, C. Hamann, P. E. Radau, and K. Tatsch, "Does combined imaging of the pre- and postsynaptic dopaminergic system increase the diagnostic accuracy in the differential diagnosis of parkinsonism?" European Journal of Nuclear Medicine and Molecular Imaging, vol. 34, no. 8, pp. 1265-1273, 2007.

[20] M. Plotkin, H. Amthauer, S. Klaffke et al., "Combined ${ }^{123} \mathrm{I}-$ FP-CIT and I-IBZM SPECT for the diagnosis of parkinsonian syndromes: study on 72 patients," Journal of Neural Transmission, vol. 112, no. 5, pp. 677-692, 2005.

[21] R. Pahwa and K. E. Lyons, "Early diagnosis of Parkinson's disease: recommendations from diagnostic clinical guidelines," The American Journal of Managed Care, vol. 16, pp. S94-99, 2010.

[22] Y. H. Weng, Y. H. W. Chou, W. S. Wu et al., "PINK1 mutation in Taiwanese early-onset parkinsonismml: clinical, genetic, and dopamine transporter studies," Journal of Neurology, vol. 254, no. 10, pp. 1347-1355, 2007.

[23] T. C. Yen, K. Y. Tzen, M. C. Chen et al., "Dopamine transporter concentration is reduced in asymptomatic Machado-Joseph disease gene carriers," Journal of Nuclear Medicine, vol. 43, no. 2, pp. 153-159, 2002.

[24] A. Antonini, "Imaging for early differential diagnosis of parkinsonism," The Lancet Neurology, vol. 9, no. 2, pp. 130131,2010
[25] C. R. Freed, P. E. Greene, R. E. Breeze et al., "Transplantation of embryonic dopamine neurons for severe Parkinson's disease," New England Journal of Medicine, vol. 344, no. 10, pp. 710-719, 2001.

[26] Y. Ma, C. Tang, T. Chaly et al., "Dopamine cell implantation in Parkinson's disease: long-term clinical and ${ }^{18} \mathrm{~F}$-FDOPA PET outcomes," Journal of Nuclear Medicine, vol. 51, no. 1, pp. 7$15,2010$.

[27] A. E. Lang, S. Gill, N. K. Patel et al., "Randomized controlled trial of intraputamenal glial cell line-derived neurotrophic factor infusion in Parkinson disease," Annals of Neurology, vol. 59, no. 3, pp. 459-466, 2006.

[28] A. L. Berry and T. Foltynie, "Gene therapy: a viable therapeutic strategy for Parkinson's disease?" Journal of Neurology, vol. 258, pp. 179-188, 2010.

[29] W. J. Marks Jr., J. L. Ostrem, L. Verhagen et al., "Safety and tolerability of intraputaminal delivery of CERE- 120 (adeno-associated virus serotype 2-neurturin) to patients with idiopathic Parkinson's disease: an open-label, phase I trial," The Lancet Neurology, vol. 7, no. 5, pp. 375-376, 2008.

[30] M. G. Kaplitt, A. Feigin, C. Tang et al., "Safety and tolerability of gene therapy with an adeno-associated virus (AAV) borne GAD gene for Parkinson's disease: an open label, phase I trial," Lancet, vol. 369, no. 9579, pp. 2097-2105, 2007.

[31] J. L. Eberling, W. J. Jagust, C. W. Christine et al., "Results from a phase I safety trial of hAADC gene therapy for Parkinson disease," Neurology, vol. 70, no. 21, pp. 1980-1983, 2008.

[32] L. Leriche, T. Björklund, N. Breysse et al., "Positron emission tomography imaging demonstrates correlation between behavioral recovery and correction of dopamine neurotransmission after gene therapy," Journal of Neuroscience, vol. 29, no. 5, pp. 1544-1553, 2009.

[33] S. I. Muramatsu, K. I. Fujimoto, S. Kato et al., "A phase I study of aromatic L-amino acid decarboxylase gene therapy for Parkinson's disease," Molecular Therapy, vol. 18, pp. 1731$1735,2010$.

[34] K. Blennow, M. J. de Leon, and H. Zetterberg, "Alzheimer's disease," Lancet, vol. 368, pp. 387-403, 2006.

[35] R. Brookmeyer, E. Johnson, K. Ziegler-Graham, and H. M. Arrighi, "Forecasting the global burden of Alzheimer's disease," Alzheimer's and Dementia, vol. 3, no. 3, pp. 186-191, 2007.

[36] A. Kadir and A. Nordberg, "Target-specific PET probes for neurodegenerative disorders related to dementia," Journal of Nuclear Medicine, vol. 51, no. 9, pp. 1418-1430, 2010.

[37] M. P. Mattson, "Pathways towards and away from Alzheimer's disease," Nature, vol. 430, no. 7000, pp. 631-639, 2004.

[38] W. Jagust, "Positron emission tomography and magnetic resonance imaging in the diagnosis and prediction of dementia," Alzheimer's and Dementia, vol. 2, no. 1, pp. 36-42, 2006.

[39] D. H. S. Silverman, G. W. Small, and M. E. Phelps, "Clinical value of neuroimaging in the diagnosis of dementia. Sensitivity and specificity of regional cerebral metabolic and other parameters for early identification of Alzheimer's disease," Clinical Positron Imaging, vol. 2, no. 3, pp. 119-130, 1999.

[40] H. Engler, A. Forsberg, O. Almkvist et al., "Two-year followup of amyloid deposition in patients with Alzheimer's disease," Brain, vol. 129, no. 11, pp. 2856-2866, 2006.

[41] A. Nordberg, "PET imaging of amyloid in Alzheimer's disease," Lancet Neurology, vol. 3, no. 9, pp. 519-527, 2004.

[42] A. Nordberg, "Amyloid imaging in Alzheimer's disease," Neuropsychologia, vol. 46, no. 6, pp. 1636-1641, 2008.

[43] A. Nordberg, "Amyloid plaque imaging in vivo: current achievement and future prospects," European Journal of 
Nuclear Medicine and Molecular Imaging, vol. 35, no. 1, pp. S46-S50, 2008.

[44] V. Valotassiou, S. Archimandritis, N. Sifakis, J. Papatriantafyllou, and P. Georgoulias, "Alzheimer's disease: SPECT and PET tracers for beta-amyloid imaging," Current Alzheimer Research, vol. 7, no. 6, pp. 477-486, 2010.

[45] K. Shoghi-Jadid, G. W. Small, E. D. Agdeppa et al., "Localization of neurofibrillary tangles and beta-amyloid plaques in the brains of living patients with alzheimer disease," American Journal of Geriatric Psychiatry, vol. 10, no. 1, pp. 24-35, 2002.

[46] C. A. Mathis, B. J. Bacskai, S. T. Kajdasz et al., "A lipophilic thioflavin-T derivative for positron emission tomography (PET) imaging of amyloid in brain," Bioorganic and Medicinal Chemistry Letters, vol. 12, no. 3, pp. 295-298, 2002.

[47] W. E. Klunk, H. Engler, A. Nordberg et al., "Imaging Brain Amyloid in Alzheimer's Disease with Pittsburgh CompoundB," Annals of Neurology, vol. 55, no. 3, pp. 306-319, 2004.

[48] R. C. Petersen, G. E. Smith, S. C. Waring, R. J. Ivnik, E. G. Tangalos, and E. Kokmen, "Mild cognitive impairment: clinical characterization and outcome," Archives of Neurology, vol. 56, no. 3, pp. 303-308, 1999.

[49] S. M. Landau, D. Harvey, C. M. Madison et al., "The Alzheimer's Disease Neuroimaging Initiative. Associations between cognitive, functional, and FDG-PET measures of decline in $\mathrm{AD}$ and MCI," Neurobiology of Aging. In press.

[50] A. Forsberg, H. Engler, O. Almkvist et al., "PET imaging of amyloid deposition in patients with mild cognitive impairment," Neurobiology of Aging, vol. 29, no. 10, pp. 1456-1465, 2008.

[51] D. F. Wong, P. B. Rosenberg, Y. Zhou et al., "In vivo imaging of amyloid deposition in Alzheimer disease using the radioligand 18F-AV-45 (flobetapir F 18)," Journal of Nuclear Medicine, vol. 51, no. 6, pp. 913-920, 2010.

[52] N. P. L. G. Verhoeff, A. A. Wilson, S. Takeshita et al., "Invivo imaging of Alzheimer disease $\beta$-amyloid with $\left[{ }^{11} \mathrm{C}\right] \mathrm{SB}-13$ PET," American Journal of Geriatric Psychiatry, vol. 12, no. 6, pp. 584-595, 2004.

[53] N. Tolboom, W. M. Van Der Flier, J. Boverhoff et al., "Molecular imaging in the diagnosis of Alzheimer's disease: visual assessment of [11C]PIB and [18F]FDDNP PET images," Journal of Neurology, Neurosurgery and Psychiatry, vol. 81, no. 8, pp. 882-884, 2010.

[54] R. Vandenberghe, K. Van Laere, A. Ivanoiu et al., "18Fflutemetamol amyloid imaging in Alzheimer disease and mild cognitive impairment: a phase 2 trial," Annals of Neurology, vol. 68, pp. 319-329, 2010.

[55] J. Hardy and D. J. Selkoe, "The amyloid hypothesis of Alzheimer's disease: progress and problems on the road to therapeutics," Science, vol. 297, no. 5580, pp. 353-356, 2002.

[56] A. Kadir, N. Andreasen, O. Almkvist et al., "Effect of phenserine treatment on brain functional activity and amyloid in Alzheimer's disease," Annals of Neurology, vol. 63, no. 5, pp. 621-631, 2008.

[57] D. E. Kuhl, S. Minoshima, K. A. Frey, N. L. Foster, M. R. Kilbourn, and R. A. Koeppe, "Limited donepezil inhibition of acetylcholinesterase measured with positron emission tomography in living Alzheimer cerebral cortex," Annals of Neurology, vol. 48, no. 3, pp. 391-395, 2000.

[58] R. V. Parsey, "Serotonin receptor imaging: clinically useful?" Journal of Nuclear Medicine, vol. 51, no. 10, pp. 1495-1498, 2010.

[59] S. Sobczak, A. Honig, M. A. van Duinen, and W. J. Riedel, "Serotonergic dysregulation in bipolar disorders: a literature review of serotonergic challenge studies," Bipolar Disorders, vol. 4, no. 6, pp. 347-356, 2002.
[60] A. Neumeister, E. Bain, A. C. Nugent et al., "Reduced serotonin type 1 receptor binding in panic disorder," Journal of Neuroscience, vol. 24, no. 3, pp. 589-591, 2004.

[61] W. C. Drevets, E. Frank, J. C. Price et al., "PET imaging of serotonin 1A receptor binding in depression," Biological Psychiatry, vol. 46, no. 10, pp. 1375-1387, 1999.

[62] W. C. Drevets, E. Frank, J. C. Price, D. J. Kupfer, P. J. Greer, and C. Mathis, "Serotonin type-1A receptor imaging in depression," Nuclear Medicine and Biology, vol. 27, no. 5, pp. 499-507, 2000.

[63] J. Blin, G. Sette, M. Fiorelli et al., "A method for the in vivo investigation in the serotonergic $5-\mathrm{HT}_{2}$ receptors in the human cerebral cortex using positron emission tomography and ${ }^{18}$ F-labeled setoperone," Journal of Neurochemistry, vol. 54, no. 5, pp. 1744-1754, 1990.

[64] J. Blin, J. C. Baron, B. Dubois et al., "Loss of brain 5-HT receptors in Alzheimer's disease. In vivo assessment with positron emission tomography and $\left[{ }^{18} \mathrm{~F}\right]$ setoperone," Brain, vol. 116, no. 3, pp. 497-510, 1993.

[65] E. T. C. Ngan, L. N. Yatham, T. J. Ruth, and P. F. Liddle, "Decreased serotonin 2A receptor densities in neurolepticnaive patients with schizophrenia: a pet study using $\left[{ }^{18} \mathrm{~F}\right]$ setoperone," American Journal of Psychiatry, vol. 157, no. 6, pp. 1016-1018, 2000.

[66] W. A. Wolf and D. M. Kuhn, "Modulation of serotonin release: interactions between the serotonin transporter and autoreceptors," Annals of the New York Academy of Sciences, vol. 604, pp. 505-513, 1990.

[67] M. Suehiro, U. Scheffel, H. T. Ravert, R. F. Dannals, and H. N. Wagner, " $[11 \mathrm{C}](+) \mathrm{McN} 5652$ as a radiotracer for imaging serotonin uptake sites with PET," Life Sciences, vol. 53, no. 11, pp. 883-892, 1993.

[68] S. Hesse, H. Barthel, J. Schwarz, O. Sabri, and U. Müller, "Advances in in vivo imaging of serotonergic neurons in neuropsychiatric disorders," Neuroscience and Biobehavioral Reviews, vol. 28, no. 6, pp. 547-563, 2004.

[69] J. H. Meyer, "Imaging the serotonin transporter during major depressive disorder and antidepressant treatment," Journal of Psychiatry and Neuroscience, vol. 32, no. 2, pp. 86-102, 2007.

[70] K. J. Lin, C. Y. Liu, S. P. Wey et al., "Brain SPECT imaging and whole-body biodistribution with $\left[{ }^{123} \mathrm{I}\right] \mathrm{ADAM}$ - a serotonin transporter radiotracer in healthy human subjects," Nuclear Medicine and Biology, vol. 33, no. 2, pp. 193-202, 2006.

[71] Z. Bhagwagar, N. Murthy, S. Selvaraj et al., "5-HTT binding in recovered depressed patients and healthy volunteers: a positron emission tomography study with $\left[{ }^{11} \mathrm{C}\right] \mathrm{DASB}, "$ American Journal of Psychiatry, vol. 164, no. 12, pp. 1858-1865, 2007.

[72] R. V. Parsey, R. S. Hastings, M. A. Oquendo et al., "Lower serotonin transporter binding potential in the human brain during major depressive episodes," American Journal of Psychiatry, vol. 163, no. 1, pp. 52-58, 2006.

[73] J. H. Meyer, A. A. Wilson, N. Ginovart et al., "Occupancy of serotonin transporters by paroxetine and citalopram during treatment of depression: a [ $\left.{ }^{11} \mathrm{C}\right] \mathrm{DASB}$ PET imaging study," American Journal of Psychiatry, vol. 158, no. 11, pp. 1843-1849, 2001.

[74] J. H. Meyer, S. Houle, S. Sagrati et al., "Brain serotonin transporter binding potential measured with $\left[{ }^{11} \mathrm{C}\right] \mathrm{DASB}$ positron emission tomography: effects of major depressive episodes and severity of dysfunctional attitudes," Archives of General Psychiatry, vol. 61, no. 12, pp. 1271-1279, 2004. 
[75] A. B. Newberg, J. D. Amsterdam, N. Wintering et al., "123 IADAM binding to serotonin transporters in patients with major depression and healthy controls: a preliminary study," Journal of Nuclear Medicine, vol. 46, no. 6, pp. 973-977, 2005.

[76] N. Herold, K. Uebelhack, L. Franke et al., "Imaging of serotonin transporters and its blockade by citalopram in patients with major depression using a novel SPECT ligand $\left[{ }^{123} \mathrm{I}\right]$-ADAM," Journal of Neural Transmission, vol. 113, no. 5, pp. 659-670, 2006.

[77] S. Sobczak, A. Honig, M. A. van Duinen, and W. J. Riedel, "Serotonergic dysregulation in bipolar disorders: a literature review of serotonergic challenge studies," Bipolar Disorders, vol. 4, no. 6, pp. 347-356, 2002.

[78] G. Murray and S. L. Johnson, "The clinical significance of creativity in bipolar disorder," Clinical Psychology Review, vol. 30, pp. 721-732, 2010.

[79] Y. H. Chou, S. J. Wang, C. L. Lin, W. C. Mao, S. M. Lee, and M. H. Liao, "Decreased brain serotonin transporter binding in the euthymic state of bipolar I but not bipolar II disorder: a SPECT study," Bipolar Disorders, vol. 12, no. 3, pp. 312-318, 2010.

[80] T. T. Chang, T. L. Yeh, N. T. Chiu et al., "Higher striatal dopamine transporters in euthymic patients with bipolar disorder: a SPECT study with [ ${ }^{99 \mathrm{~m}} \mathrm{Tc}$ ] TRODAT-1," Bipolar Disorders, vol. 12, no. 1, pp. 102-106, 2010.

[81] Y. K. Yang, W. J. Yao, T. L. Yeh, I. H. Lee, K. C. Chen, and R. B. Lu, "Association between serotonin transporter availability and hostility scores in healthy volunteers-a single photon emission computed tomography study with [ $\left.{ }^{123} \mathrm{I}\right]$ ADAM," Psychiatry Research, vol. 154, no. 3, pp. 281-284, 2007.

[82] C. Hiemke, "Therapeutic drug monitoring in neuropsychopharmacology: does it hold its promises?" European Archives of Psychiatry and Clinical Neuroscience, vol. 258, no. 1, supplement, pp. 21-27, 2008.

[83] M. Sekine, R. Arakawa, H. Ito et al., "Norepinephrine transporter occupancy by antidepressant in human brain using positron emission tomography with $(\mathrm{S}, \mathrm{S})-\left[{ }^{18} \mathrm{~F}\right] \mathrm{FMeNER}-\mathrm{D}$," Psychopharmacology, vol. 210, pp. 331-336, 2010.

[84] Y. S. Ding, T. Singhal, B. Planeta-Wilson et al., "PET imaging of the effects of age and cocaine on the norepinephrine transporter in the human brain using $(\mathrm{S}, \mathrm{S})$ $\left[{ }^{11} \mathrm{C}\right] \mathrm{O}$-methylreboxetine and HRRT," Synapse, vol. 64 , no. 1 , pp. 30-38, 2010.

[85] M. Árgyelán, Z. Szabó, B. Kanyó et al., “Dopamine transporter availability in medication free and in bupropion treated depression: a ${ }^{99 m}$ Tc-TRODAT-1 SPECT study," Journal of Affective Disorders, vol. 89, no. 1-3, pp. 115-123, 2005.

[86] L. Farde, F. A. Wiesel, C. Halldin, and G. Sedvall, "Central D2-dopamine receptor occupancy in schizophrenic patients treated with antipsychotic drugs," Archives of General Psychiatry, vol. 45, no. 1, pp. 71-76, 1988. 


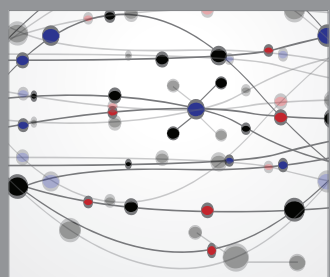

The Scientific World Journal


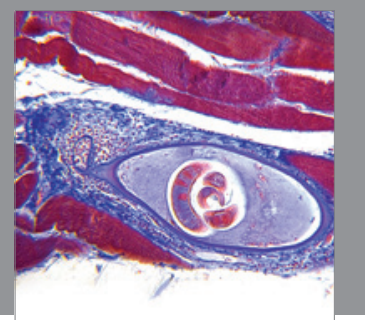

Gastroenterology

Research and Practice
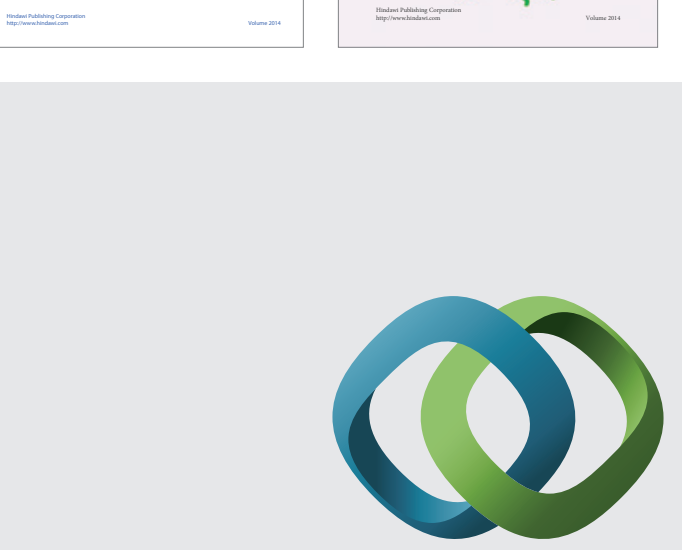

\section{Hindawi}

Submit your manuscripts at

http://www.hindawi.com
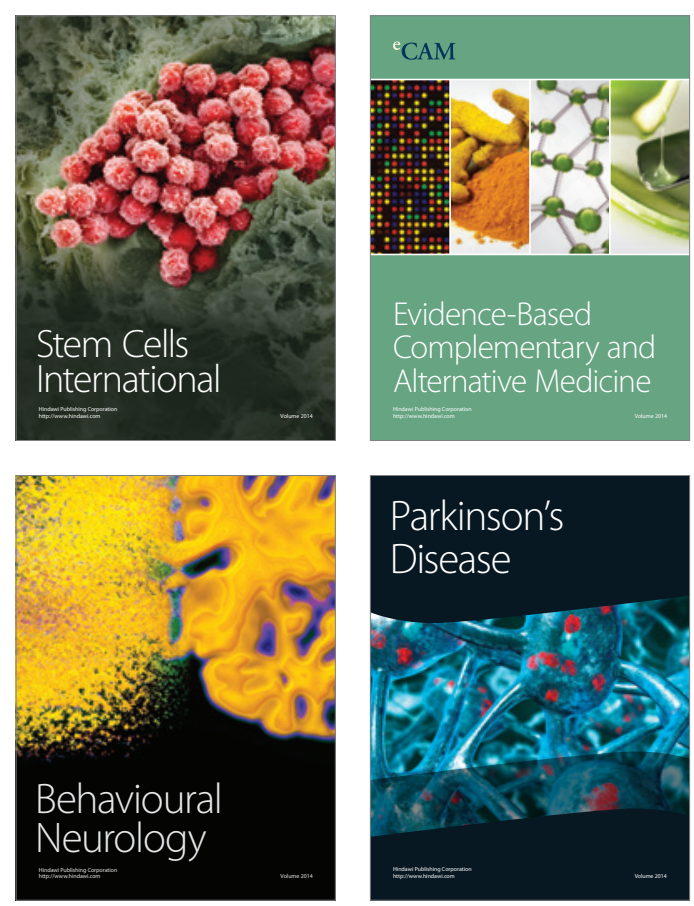



Journal of
Diabetes Research

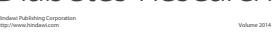

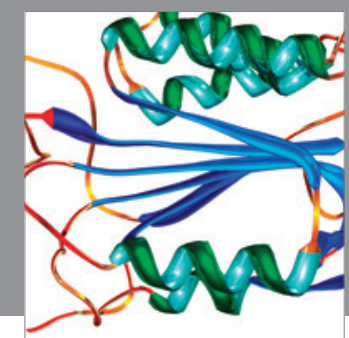

Disease Markers
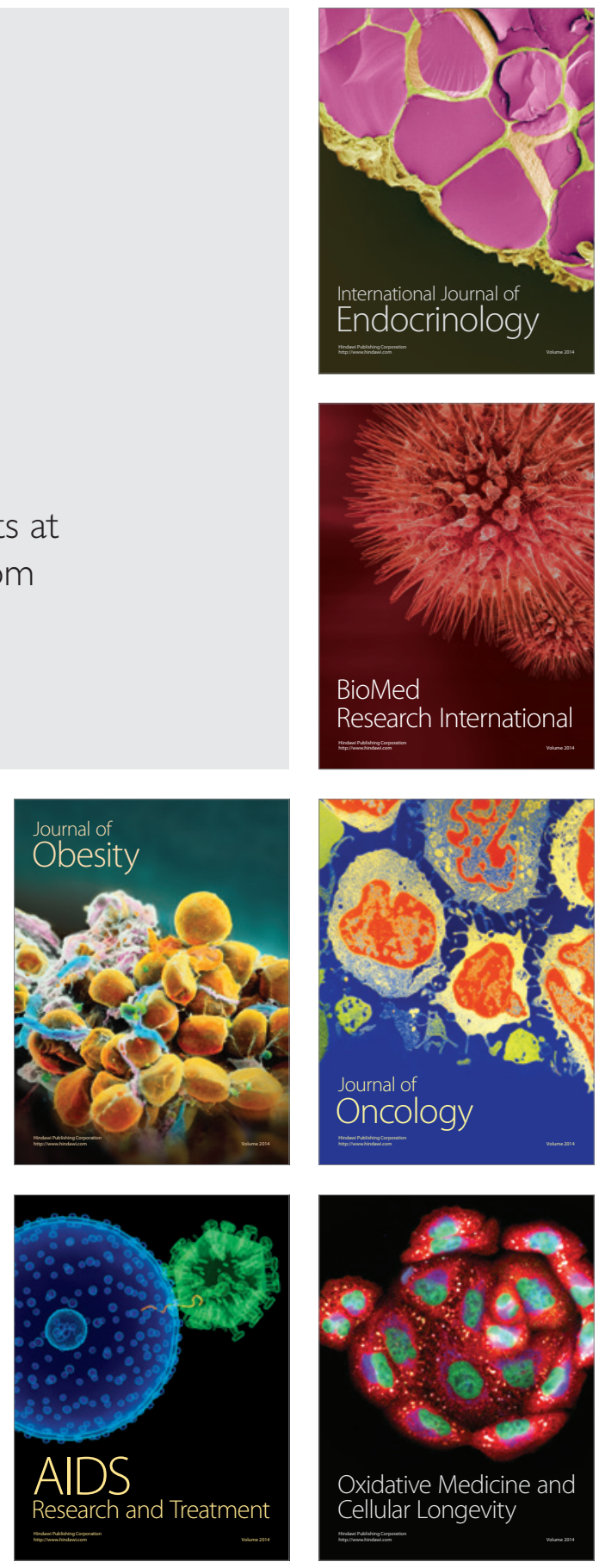